\title{
Analysis of Control Strategy for Hybrid Active Power Filter
}

\author{
VanBao Chau ${ }^{1}$, CongPhuong Vo ${ }^{1}$, MinhThuyen $\mathrm{Chau}^{2, *}$ \\ ${ }^{1}$ Faculty of Electrical \& Electronic Engineering - Ho Chi Minh City University of Transport, Viet Nam \\ ${ }^{2}$ Faculty of Electrical Engineering - Industrial University of Ho Chi Minh City, Viet Nam \\ Corresponding author
}

\begin{abstract}
The hybrid active power filter is very efficient in filtering harmonics and power factor correction. But its efficiency depends on many factors; including control strategy plays a very important role. Therefore, this paper aims to analyze mathematical model of the hybrid active power filter. On that basis, a comparison between the control strategy according to the load harmonic current and source harmonic current have done. The simulation results have proven to be that: control strategy according to the load harmonic current is more effective the control strategy according to the source harmonic current. This analysis will be the basis of the researches in control of the hybrid active power filter.
\end{abstract}

Keywords-hybrid active powe filter; control strategy; harmonics; active power filter; reactive power filter

\section{INTRODUCTION}

In power systems, power quality issues have always been concerned and have been the countries in the world are always looking to improve further. One of the main reasons making the power quality is deteriorated because the harmonics are generated from the non-linear loads. The presence of harmonics in the system will be the cause of the problem: the loss of power, distortion of voltage, overheating ... Therefore, to improve power quality, the active filter circuits (Active Power Filter-APF) [1-2] was born in the late 1970s. The most basic structure of APF is a parallel connection with non-linear load to filter the harmonic components of load and correct power factor. The biggest advantage of the APF is the ability to flexibly compensate, does not occur resonance with the grid impedance. However the APF also exists many disadvantages such as high cost, low capacity and difficult to use in the highvoltage grid. To improve the above defects, the hybrid active power filter circuits (HAPF) [3-4] birth is a necessary. Its structure is a combination of the PPFs and APF, so it has all the advantages of both the PPF and the APF. The most prominent advantage of HAPF is it capable of working in the high-voltage grid and large capacity with a capacity of the APF is relatively small.

Currently, also has many research about HAPF, especially about its control strategy and often the researches are based on the load harmonic current [5-8] and the source harmonic current [9-10]. However, do not yet have a paper would give a general analysis of the control strategy for HAPF. With the parameters are known, the selection of control strategy would be most effective? By the way, this paper is based on mathematical model of the HAPF to perform an analysis of the control strategies of HAPF, the influence of each parameter up control effectiveness of HAPF.

\section{MATHEMATICAL MOdEL AND CONTROL STRATEGY FOR HAPF}

Structure of HAPF is shown as in Figure I.

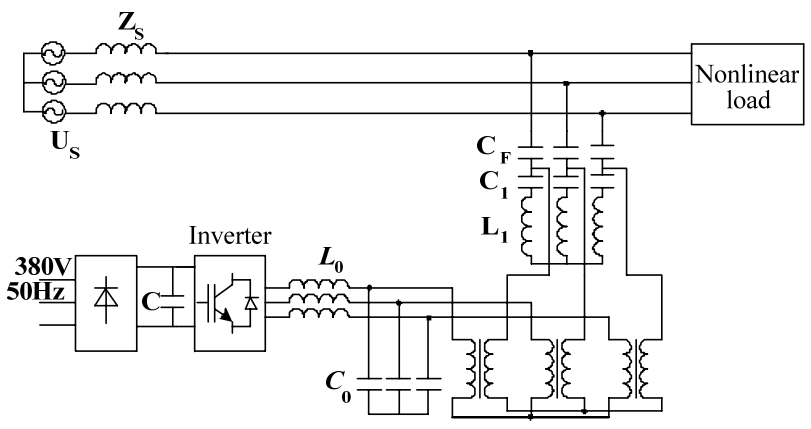

FIGURE I. STRUCTURE OF HAPF

The structure of a HAPF consists of four parts: the rectifier - inverter, output filter, ideal transformer and added circuit $\mathrm{C}_{1}$ $\mathrm{L}_{1}-\mathrm{C}_{\mathrm{F}}$. An ideal transformer has transformer ratio is $\mathrm{n}: 1$ placed between the output circuit and the added circuit. To reduce the capacity of the APF, a resonant circuit at basic frequency $\mathrm{L}_{1}-\mathrm{C}_{1}$ is connected with a capacitance $\mathrm{C}_{\mathrm{F}}$.

The single-phase equivalent circuit of HAPF is shown in Figure II.

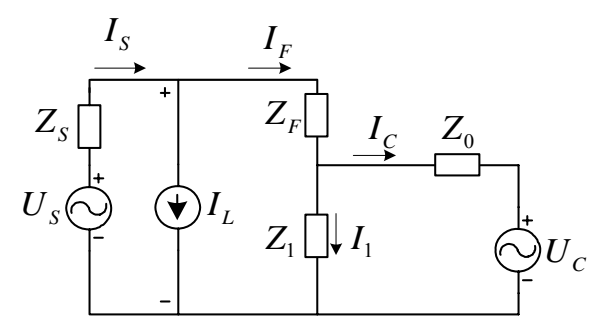

FIGURE II. SINGLE-PHASE EQUIVALENT OF HAPF

$$
\text { Where: }\left\{\begin{array}{l}
Z_{S}=R_{S}+j \omega L_{S} ; Z_{1}=1 / j \omega C_{1}+j \omega L_{1} ; \\
Z_{0}=\left[j \omega L_{0} / /\left(1 / j \omega C_{0}\right)\right] / n^{2} ; Z_{F}=1 / j \omega C_{F}
\end{array}\right.
$$

From Figure II, I calculated as follows: 


$$
\begin{aligned}
& \mathrm{I}_{\mathrm{S}}=\frac{\mathrm{U}_{\mathrm{S}}-\mathrm{K}_{1} \mathrm{U}_{\mathrm{C}}+\left(\mathrm{K}_{2}+\mathrm{Z}_{\mathrm{F}}\right) \mathrm{I}_{\mathrm{L}}}{\mathrm{K}_{2}+\mathrm{Z}_{\mathrm{F}}+\mathrm{Z}_{\mathrm{S}}}(1) \\
& \text { with } \mathrm{K}_{1}=\frac{\mathrm{Z}_{1}}{\mathrm{Z}_{0}+\mathrm{Z}_{1}} ; \mathrm{K}_{2}=\frac{\mathrm{Z}_{0} \mathrm{Z}_{1}}{\mathrm{Z}_{0}+\mathrm{Z}_{1}}
\end{aligned}
$$

Based on (1) the following cases are considered with different frequencies: $100 \mathrm{~Hz}, 150 \mathrm{~Hz}, 250 \mathrm{~Hz}$ and $350 \mathrm{~Hz}$. The parameters of the HAPF are listed as in Table I.

TABLE I. TABLE I. PARAMETERS OF HAPF

\begin{tabular}{|c|c|c|c|c|c|c|c|}
\hline $\mathrm{C}_{\mathrm{F}} \boldsymbol{\mu} \boldsymbol{F}$ & $\mathrm{C}_{\boldsymbol{1}} \boldsymbol{\mu} \boldsymbol{F}$ & $\mathrm{L}_{\mathbf{1}} \boldsymbol{m H}$ & $\mathrm{L}_{\mathbf{0}} \boldsymbol{m H}$ & $\mathrm{C}_{\mathbf{0}} \boldsymbol{\mu} \boldsymbol{F}$ & $\mathrm{L}_{\mathrm{s}} \boldsymbol{m H}$ & $\begin{array}{c}\mathbf{R}_{\mathrm{s}} \\
\boldsymbol{\Omega}\end{array}$ & $\boldsymbol{n}$ \\
\hline 100 & 338 & 30 & 1 & 60 & 0.2 & 0.01 & 1 \\
\hline
\end{tabular}

The effectiveness of control strategies are analyzed as follows:

A. Control Srategy Based on the Source Harmonic Current: $U_{c}=K I_{s}$ ( $K$ is controlled gain)

Substitute $\mathrm{U}_{\mathrm{c}}=\mathrm{KI}_{\mathrm{s}}$ into (1) we calculated out:

$$
\mathrm{I}_{\mathrm{S}}=\frac{\left(\mathrm{K}_{2}+\mathrm{Z}_{\mathrm{F}}\right) \mathrm{I}_{\mathrm{L}}+\mathrm{U}_{\mathrm{S}}}{\mathrm{K}_{2}+\mathrm{Z}_{\mathrm{F}}+\mathrm{Z}_{\mathrm{S}}+\mathrm{KK}_{1}}(2)
$$

(3)

Case 1: The influence of $\mathrm{I}_{\mathrm{L}}$ on $\mathrm{I}_{\mathrm{S}}$ will be considered as in Eq.

$$
\eta_{1} \%=\frac{\partial \mathrm{I}_{\mathrm{S}}}{\partial \mathrm{I}_{\mathrm{L}}} \cdot 100=\frac{\mathrm{K}_{2}+\mathrm{Z}_{\mathrm{F}}}{\mathrm{K}_{2}+\mathrm{Z}_{\mathrm{F}}+\mathrm{Z}_{\mathrm{S}}+\mathrm{KK}_{1}} \cdot 100(3)
$$

Based on (3), the influence of $I_{L}$ on $I_{s}$ be demonstrated as in Figure III

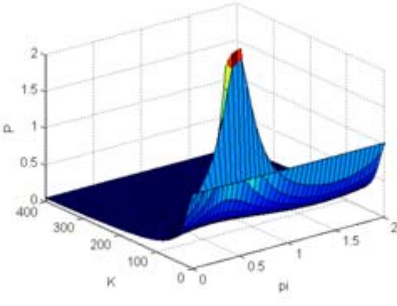

(a) $\mathrm{f}=100 \mathrm{~Hz}$

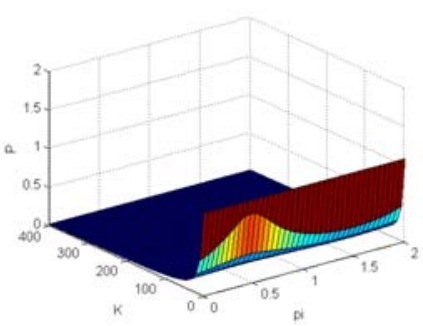

(c) $\mathrm{f}=250 \mathrm{~Hz}$

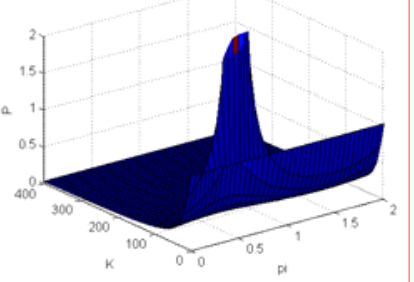

(b) $\mathrm{f}=150 \mathrm{~Hz}$

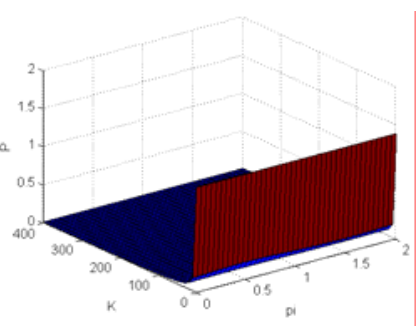

(d) $\mathrm{f}=350 \mathrm{~Hz}$
FIGURE III. INFLUENCE OF $\mathrm{I}_{\mathrm{L}} \mathrm{ON} \mathrm{I}_{\mathrm{S}}$
Case 2: The influence of $\mathrm{U}_{\mathrm{s}}$ on $\mathrm{I}_{\mathrm{s}}$

The influence of $U_{s}$ on $I_{s}$ will be considered as in Eq. (4)

$$
\eta_{2} \%=\frac{\partial I_{S}}{\partial U_{s}} \cdot 100=\frac{1}{K_{2}+Z_{F}+Z_{S}+K_{1}} \cdot 100
$$

Based on (4), the influence of $U_{s}$ on $I_{s}$ be demonstrated as in Figure IV

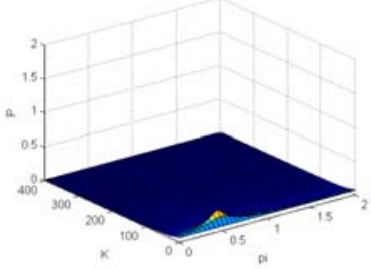

(a) $\mathrm{f}=100 \mathrm{~Hz}$

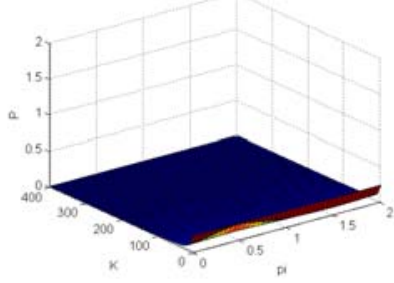

(c) $\mathrm{f}=250 \mathrm{~Hz}$

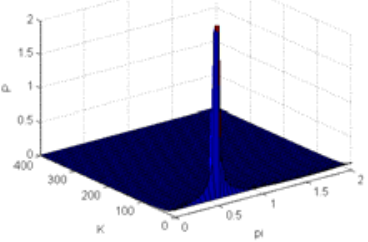

(b) $\mathrm{f}=150 \mathrm{~Hz}$

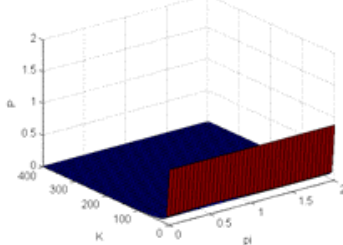

(d) $\mathrm{f}=350 \mathrm{~Hz}$
FIGURE IV. INFLUENCE OF $\mathrm{U}_{\mathrm{S}} \mathrm{ON} \mathrm{I}_{\mathrm{S}}$

Case 3: The influence of $Z_{\mathrm{s}}$ on $\mathrm{I}_{\mathrm{s}}$

The influence of $Z_{s}$ on $I_{s}$ will be considered as in Eq. (5)

Based on (5), the influence of $Z_{s}$ on $I_{s}$ be demonstrated as in Figure V.

$\eta_{3} \%=\frac{\partial^{2} I_{S}}{\partial Z_{S} \partial I_{L}} \cdot 100=-\frac{K_{2}+Z_{F}}{\left(K_{2}+Z_{F}+Z_{S}+K_{1}\right)^{2}} \cdot 100(5)$

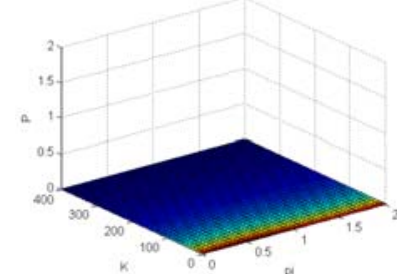

(a) $\mathrm{f}=100 \mathrm{~Hz}$

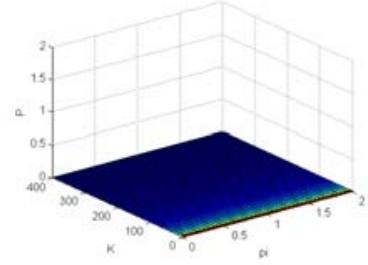

(c) $\mathrm{f}=250 \mathrm{~Hz}$

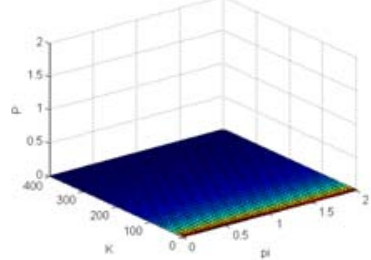

(b) $\mathrm{f}=150 \mathrm{~Hz}$

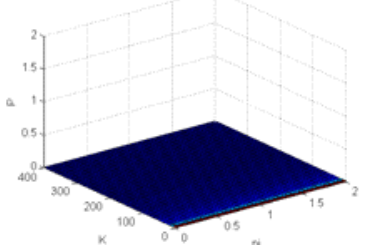

(d) $\mathrm{f}=350 \mathrm{~Hz}$
FIGURE V. INFLUENCE $Z_{\mathrm{s}}$ ON Is 
B. Control Strategy Based on the Load Harmonic Current $I_{L}$ :

Substitute $\mathrm{U}_{\mathrm{c}}=\mathrm{KI}_{\mathrm{L}}$ into (1) we calculated out:

$$
I_{S}=\frac{U_{S}+\left(K_{2}+Z_{F}-K \cdot K_{1}\right) I_{L}}{K_{2}+Z_{F}+Z_{S}}(6)
$$

Case 1: The influence of $I_{L}$ on $I_{S}$

The influence of $\mathrm{I}_{\mathrm{L}}$ on $\mathrm{I}_{\mathrm{s}}$ will be considered as in Eq. (7)

$$
\eta_{1} \%=\frac{\partial I_{S}}{\partial I_{L}} \cdot 100=\frac{K_{2}-K_{1}+Z_{F}}{Z_{S}+Z_{F}+K_{2}} \cdot 100(7)
$$

Based on (7), the influence of $\mathrm{I}_{\mathrm{L}}$ on $\mathrm{I}_{\mathrm{s}}$ be demonstrated as in Figure VI.

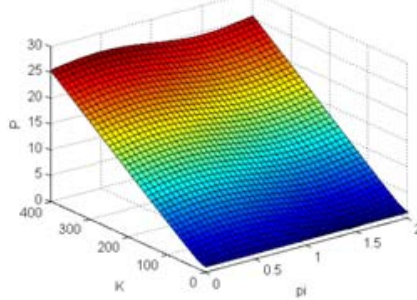

(a) $\mathrm{f}=100 \mathrm{~Hz}$

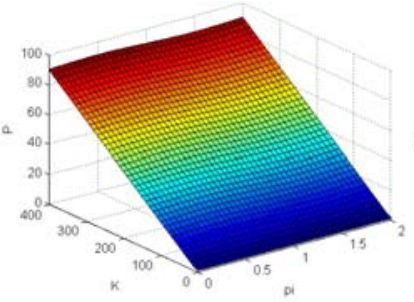

(c) $\mathrm{f}=250 \mathrm{~Hz}$

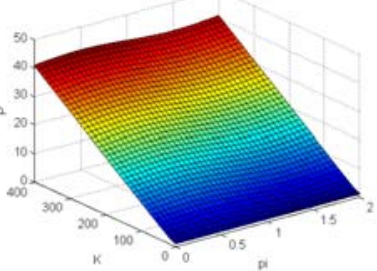

(b) $\mathrm{f}=150 \mathrm{~Hz}$

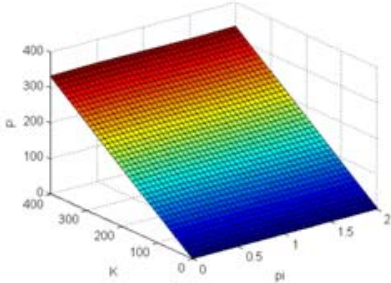

(d) $\mathrm{f}=350 \mathrm{~Hz}$
FIGURE VI. FIGURE 6. INFLUENCE OF $\mathrm{I}_{\mathrm{L}} \mathrm{ON} \mathrm{I}_{\mathrm{S}}$

Case 2: The influence of $U_{s}$ on $I_{s}$

The influence of $U_{s}$ on $I_{s}$ will be considered as in Eq. (8)

$$
\eta_{2} \%=\frac{\partial I_{S}}{\partial U_{S}} \cdot 100=\frac{1}{K_{2}+Z_{F}+Z_{S}} \cdot 100(8)
$$

Based on (8), the influence of $U_{s}$ on $I_{s}$ be demonstrated as in Figure VII

Case 3: The influence of Zs on Is

The influence of $Z_{\mathrm{s}}$ on $\mathrm{I}_{\mathrm{s}}$ will be considered as in Eq. (9)

$$
\eta_{3} \%=\frac{\partial^{2} I_{S}}{\partial Z_{S} \partial I_{L}} \cdot 100=-\frac{K_{2}-K_{1}+Z_{F}}{\left(K_{2}+Z_{F}+Z_{S}\right)^{2}} \cdot 100(9)
$$

Based on (9), the influence of $Z_{s}$ on $I_{s}$ be demonstrated as in Figure VIII.

In summary, from the results of the graphs from Figure 3 to Figure 8, we can notice that: the control strategies $U_{c}=K_{L}$ is more effective the control strategies $\mathrm{U}_{\mathrm{c}}=\mathrm{KI}_{\mathrm{s}}$. In Figure 6 and Figure 8: when $\mathrm{K}$ increase then $\mathrm{P}$ also increased, the relationship between $\mathrm{K}$ and $\mathrm{P}$ is almost linear, the waveform does not exist the extremes, not been modified unexpectedly. Therefore, the control strategy $\mathrm{U}_{\mathrm{c}}=\mathrm{KI}_{\mathrm{L}}$ will be very efficient.

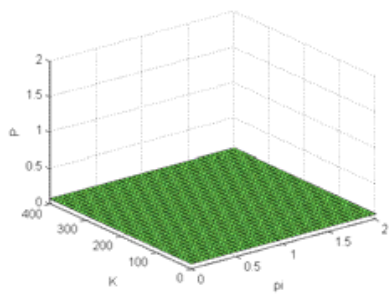

(a) $\mathrm{f}=100 \mathrm{~Hz}$

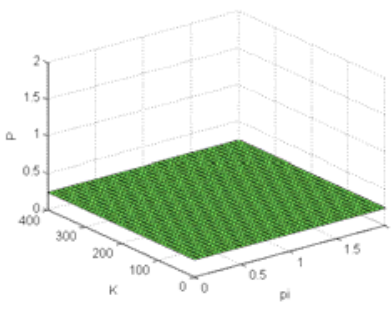

(c) $\mathrm{f}=250 \mathrm{~Hz}$

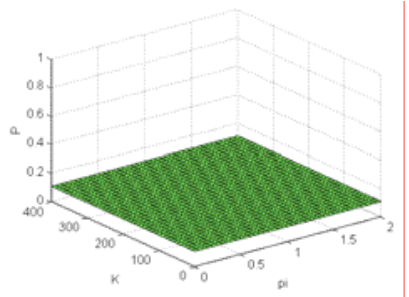

(b) $\mathrm{f}=150 \mathrm{~Hz}$

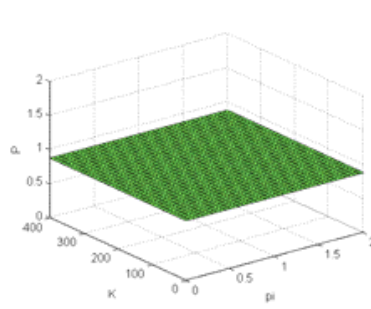

(d) $\mathrm{f}=350 \mathrm{~Hz}$

FIGURE VII. INFLUENCE $\mathrm{US}_{\mathrm{S}} \mathrm{ON} \mathrm{I}_{\mathrm{S}}$

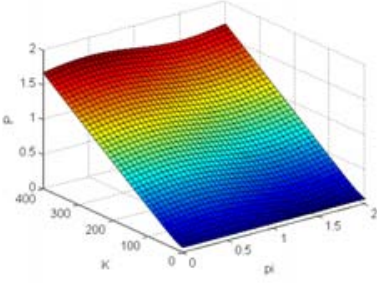

(a) $\mathrm{f}=100 \mathrm{~Hz}$

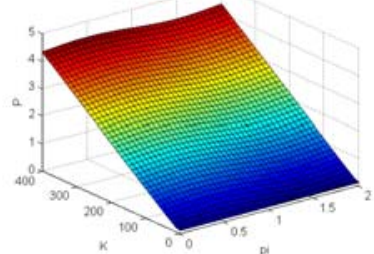

(b) $\mathrm{f}=150 \mathrm{~Hz}$

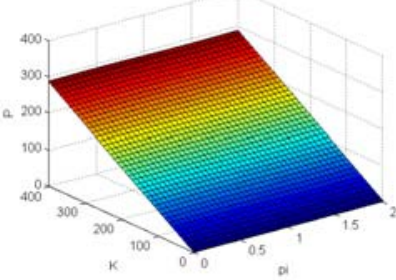

(d) $\mathrm{f}=350 \mathrm{~Hz}$

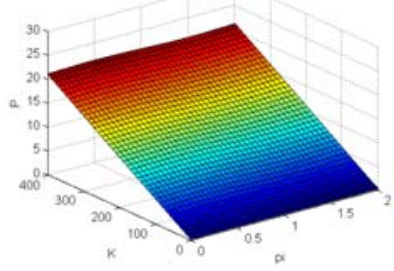

(c) $\mathrm{f}=250 \mathrm{~Hz}$
FIGURE VIII. INFLUENCE OF ZS ON IS $\left(\eta_{3}\right)$

\section{SimUlation RESUlTS}

To demonstrate the effectiveness of control strategies $\mathrm{U}_{\mathrm{c}}=\mathrm{KI}_{\mathrm{s}}$ and $\mathrm{U}_{\mathrm{c}}=\mathrm{KI}_{\mathrm{L}}$. The simulation results are made for a system HAPF $380 \mathrm{~V}-50 \mathrm{~Hz}$. The parameters of the HAPF model are given in table I. 
Before Kincreased the simulation results of the control strategy $\mathrm{U}_{\mathrm{c}}=\mathrm{KI}_{\mathrm{s}}$ and $\mathrm{U}_{\mathrm{c}}=\mathrm{KI}_{\mathrm{L}}$ are represented as in Figure IX and FigureX.

When $\mathrm{K}$ increased, simulation results of the control strategy $\mathrm{U}_{\mathrm{c}}=\mathrm{KI}_{\mathrm{s}}$ and $\mathrm{U}_{\mathrm{c}}=\mathrm{KI}_{\mathrm{L}}$ are demonstrated as in Figure XI and FigureXII.

From the simulation results we can see that: when $\mathrm{K}$ increase, the control strategy $\mathrm{U}_{\mathrm{c}}=\mathrm{KI}_{\mathrm{s}}$ less effective the control strategy $\mathrm{U}_{\mathrm{c}}=\mathrm{KI}_{\mathrm{L}}$. However, when $\mathrm{K}$ increases also needs to notice to the conditions of the system stability.

The summary table the effectiveness of these strategies in steady-state is shown as in Table II.

TABLE II. SUMMARY TABLE THE EFFECTIVENESS OF THESE STRATEGIES IN STEADY-STATE

\begin{tabular}{|l|c|c|}
\hline \multirow{2}{*}{ Strategies } & Before K increasing & After K increasing \\
\cline { 2 - 3 } & $\mathrm{THD} \mathrm{I}_{\mathrm{s}} \%$ & THD I $_{\mathrm{s}} \%$ \\
\hline$U_{C}=K I_{S}$ & $8.85 \%$ & $7.0 \%$ \\
\hline$U_{C}=K I_{L}$ & $5.78 \%$ & $1.64 \%$ \\
\hline
\end{tabular}
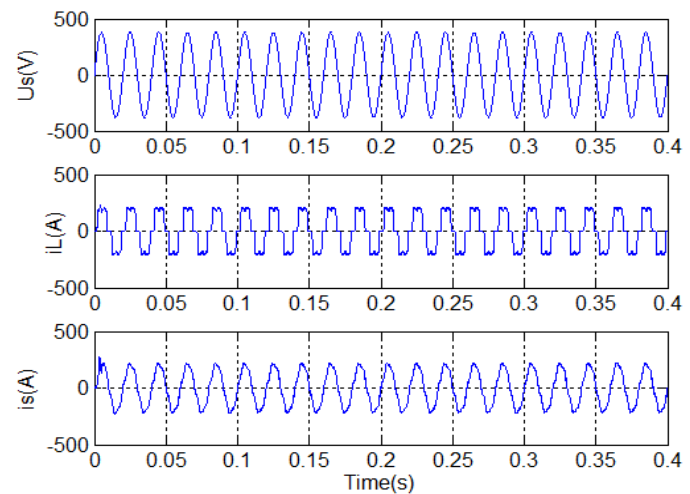

FIGURE IX. SIMULATION RESULT BEFORE INCREASING K WITH $\mathrm{U}_{\mathrm{C}}=\mathrm{KI}_{\mathrm{S}}$
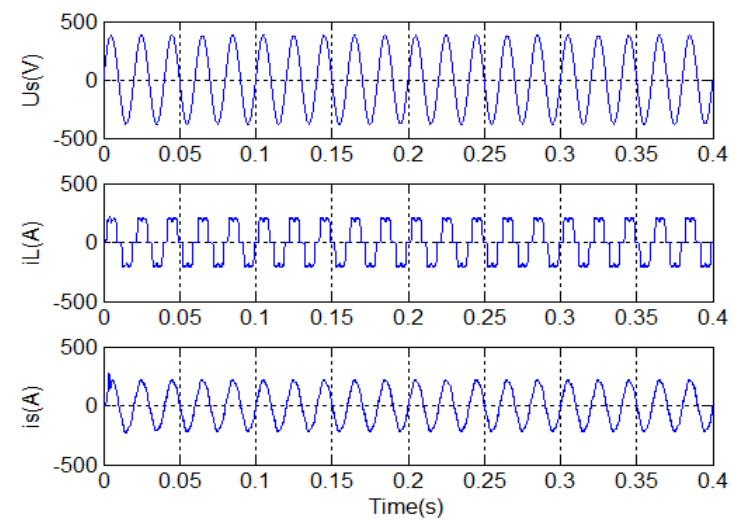

FIGURE X. FIGURE 10. SIMULATION RESULT BEFORE INCREASING $\mathrm{K}$ WITH $\mathrm{U}_{\mathrm{C}}=\mathrm{KI}_{\mathrm{L}}$
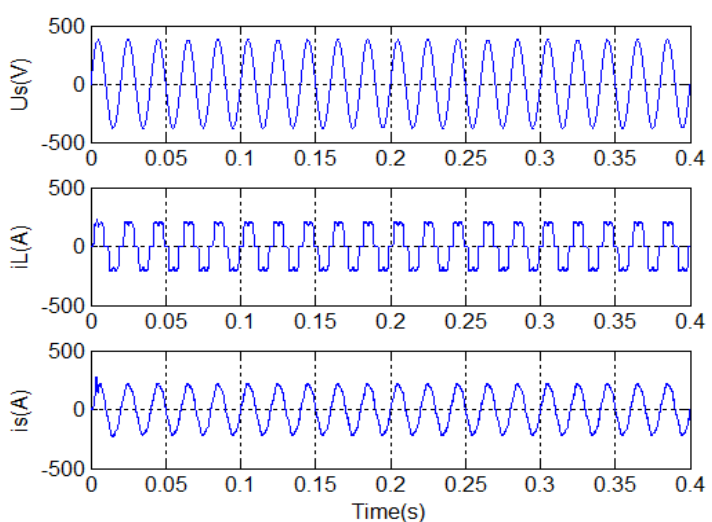

FIGURE XI. SIMULATION RESULT AFTER INCREASING K WITH $\mathrm{U}_{\mathrm{C}}=\mathrm{KI}_{\mathrm{S}}$
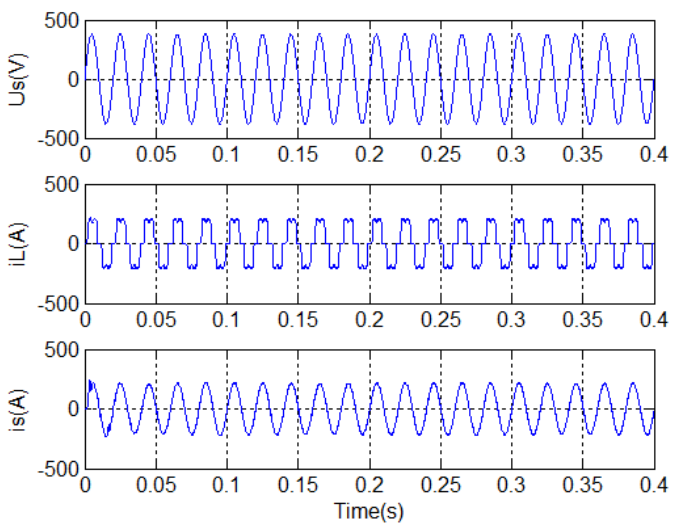

FIGURE XII. SIMULATION RESULT AFTER INCREASING K WITH $\mathrm{U}_{\mathrm{C}}=\mathrm{KI}_{\mathrm{L}}$

\section{CONCLUSION}

The paper has been analysis mathematical model for a form $\mathrm{HAPF}$, demonstrated the influence of each parameter to operate of HAPF. The simulation results show the efficiency of each control strategy. This analysis will be the basis for the decision to choose control method, improve work efficiency for HAPF.

\section{REFERENCES}

[1] $\mathrm{Hu}$ Ming and Chen Heng, "Active power filter technology and its application," Automation of Electric Power Systems, vol. 5, pp. 66-70, 2000 .

[2] Tzung-Lin Lee, Yen-Ching Wang, Jian-Cheng Li, Guerrero. J M, " Hybrid Active Filter With Variable Conductance for Harmonic Resonance Suppression in Industrial Power Systems," IEEE Transactions on Power Electronics, vol. 62, pp. 746 - 756, 2015.

[3] Wai-Hei Choi, Chi-Seng Lam, Man-Chung Wong; Ying-Duo Han, "Analysis of DC-Link Voltage Controls in Three-Phase Four-Wire Hybrid Active Power Filters," IEEE Transactions on Power Electronics, vol. 28, pp. 2180 - 2191, 2013.

[4] Yang Han, Lin Xu, Khan M. M, Chen Chen, Gang Yao andLi-Dan Zhou, "Robust Deadbeat Control Scheme for a Hybrid APF With Resetting Filter and ADALINE-Based Harmonic Estimation Algorithm," IEEE Transactions on Industrial Electronics, vol. 58, pp. 3893 - 3904, 2011.

[5] An Luo, Zhikang Shuai, Wenji Zhu, Ruixiang Fan, Chunming Tu, "Development of Hybrid Active Power Filter Based on the Adaptive Fuzzy Dividing Frequency-Control Method," IEEE transactions on power delivery, vol. 24, pp. 424-432, 2009. 
[6] Chen Wei, LI Qin, Lu Tingjin, Rong Penghui, Zhao Yanqing, "Method of Event Detection Based on Dynamic Hybrid Fuzzy Logic System," International Conference on Intelligent Computation Technology and Automation, pp. 661-663, 2010.

[7] Haihong Huang, Huan Xue, Xin Liu, Haixin Wang,"The study of Active Power Filter using a universal harmonic detection method,'IEEE ECCE Asia Downunder (ECCE Asia), pp. 591 - 595, 2013.

[8] Liu Wei, Zhang Dawei, "Study on a series hybrid activepowerfilter based on novel fuzzy immune PID controller," International Conference on Measurement, Information and Control, pp. 520-523, 2012.

[9] Demirdelen T, Inci M, Bayindir K C, Tumay M,"Review of Hybrid Active Power Filter Topologies and Controllers," Power Engineering, Energy and Electrical Drives (POWERENG), pp. 587 - 592, 2013.

[10] TrungNhan Nguyen, An Luo, Zhikang Shuai, MinhThuyen Chau, MingFei $\mathrm{Li}$ and LeMing Zhou, "Generalised design method for improving controlquality of hybrid active power filter with injection Circuit," IET Power Electron, vol. 7, pp. 1204-1215, 2014. 